\title{
Prediksi Kelalaian Pinjaman Bank Menggunakan Random Forest dan Adaptive Boosting
}

\author{
http://dx.doi.org/10.28932/jutisi.v6i1.2313
}

\author{
Joseph Sanjaya $^{\# 1}$, Erick Renata ${ }^{\# 2}$, Vincent Elbert Budiman ${ }^{\# 3}$, Francis Anderson ${ }^{\# 4}$, Mewati Ayub ${ }^{\# 5}$ \\ \#Jurusan Magister Ilmu Komputer, Universitas Kristen Maranatha \\ Jl. Surya Sumantri No.65, Sukawarna \\ ${ }^{1}$ mi1879011@student.it.maranatha.edu \\ ${ }^{2}$ mi1879010@student.it.maranatha.edu \\ ${ }^{3}$ mi1879007@student.it.maranatha.edu \\ ${ }^{4}$ mi1879015@student.it.maranatha.edu \\ ${ }^{5}$ mewati.ayub@it.maranatha.edu
}

\begin{abstract}
A loan is one of the most important products on the bank, which used for main revenue. All bank tries to find the most effective business strategy to persuade a customer to use the loan, but loan default has a negative effect after the application is approved. Loan default causes loss on the bank, therefore it is mandatory to calculate in order to decrease the risk of the loan default. This study uses the random forest and adaptive boosting machine learning methods to get the prediction and decision. The random forest uses a voting method from many decision trees and adaptive boosting can support to increase accuracy, stability and handle an underfit or overfit problem. The experimental results show that Adaptive Boosted Random Forest outperformed normal random forest and Deep learning Neural Network (DNN) in recall rate evaluation metrics with small trade-offs in the accuracy.
\end{abstract}

Keywords - Adaptive Boosting; Bank; Loan Default; Machine learning; Random Forest;

\section{Pendahuluan}

Pinjaman adalah produk yang penting pada bank, dimana pinjaman merupakan prioritas utama pemasukan utama pada bank, tetapi seringkali pinjaman berdampak negatif di saat peminjam tidak bisa melunaskan pinjamannya atau disebut kredit macet. Peristiwa kredit macet adalah peristiwa negatif pada bank yaitu kerugian. Terlalu banyak kredit macet pun dapat menjadi suatu penilaian bank, dimana, menurut peraturan PBI Nomor 6/10/PBI/2004 tanggal 12 April 2004 mengenai Non-Perform Loan (NPL), suatu bank diharuskan memiliki NPL dibawah $5 \%$. Ada banyak faktor yang dapat memengaruhi macetnya kredit, maka dalam penelitian ini akan dilakukan pembelajaran menggunakan pembelajaran mesin. Dengan menggunakan pembelajaran mesin, diharapkan fitur dan faktor yang memengaruhi suatu pinjaman menjadi kredit macet dapat terlihat. Metode yang akan digunakan adalah metode random forest, yaitu metode voting pada banyak pohon pengambilan keputusan. Menurut Cuiqing Jiang, random forest merupakan metode yang baik untuk memprediksi loan default dikarenakan memiliki akurasi yang tinggi dan terhindar dari overfitting, selain itu, digunakan metode adaboost juga, untuk meningkatkan akurasi, stabilitas, dan masalah overfit dan underfit [9].

Berikut ini merupakan 3 hal yang menjadi fokus permasalahan:

a. Masalah kredit macet merupakan fokus utama di dalam penelitian ini, penelitian diharapkan dapat menghasilkan prediksi loan default customer sehingga dapat mengurangi kemungkinan terjadinya huge loss pada perbankan.

b. Performa dari model prediksi loan default yang akan digunakan pada penelitian ini.

c. Keadaan bank yang diteliti berdasarkan risk assessment NPL (Non-Perform Loan).

Berdasarkan fokus permasalahan yang dijabarkan diatas, berikut tujuan dari penelitian yang dilakukan:

a. Merancang sistem prediksi loan default customer sehingga dapat mengurangi kemungkinan terjadinya huge loss pada perbankan. Diharapkan penelitian dapat menghasilkan model yang memiliki akurasi dan recall rate yang tinggi.

b. Mendapatkan hasil benchmarking pada performa model yang diajukan.

c. Menganalisis keadaan bank yang diteliti berdasarkan risk assessment NPL.

Penelitian ini diharapkan memiliki beberapa manfaat, yakni:

a. mengenali cara pemodelan algoritma Random forest dan Adaboost untuk Prediksi, 
b. mengurangi resiko terjadinya loan default pada perbankan yang dapat menyebabkan huge loss pada bank,

c. memberikan prediksi negative behavior customer sehingga data dapat dipakai untuk membuat keputusan dengan tingkat risk rendah,

d. membuat proses loan auditing lebih cepat, karena sudah menggunakan machine learning (tidak manual).

\section{KAJIAN LITERATUR}

\section{A. Machine learning}

Machine learning adalah algoritma atau model statistik yang berfungsi untuk melakukan tugas spesifik tanpa suatu instruksi dengan mengandalkan "pattern". Algoritma machine learning akan membuat suatu model matematis berdasarkan data, yang biasa disebut "data training", yang digunakan untuk membuat suatu prediksi atau melakukan keputusan tanpa harus secara eksplisit diprogramkan untuk melakukan hal tersebut [4].

Machine learning dibagi menjadi dua, yakni unsupervised learning dan supervised learning. Supervised learning merupakan pembelajaran menggunakan data yang mengandung input serta output yang diinginkan. Klasifikasi dan Regresi merupakan bentuk dari supervised learning. Algoritma Klasifikasi berguna untuk memisahkan dan mengelompokkan data untuk melakukan prediksi sebagaimana akan digunakan pada Loan Prediction.

Unsupervised learning merupakan pembelajaran menggunakan data yang hanya memiliki input tetapi tidak mempunyai output spesifik. Fungsi utama dari unsupervised learning adalah menemukan fitur atau pattern dan akan mengkategorikan hasilnya sebagai prediksi [12].

\section{B. Data Analytics (DA)}

Data Analytics (DA) adalah proses memeriksa kumpulan data (data set) untuk menarik kesimpulan tentang informasi yang dikandungnya. DA digunakan dalam industri komersial untuk memungkinkan organisasi membuat keputusan bisnis yang lebih tepat dan oleh para ilmuwan atau peneliti untuk memverifikasi atau menyangkal model, teori, dan atau hipotesis ilmiah.

Inisiatif Data Analytics dapat membantu pebisnis meningkatkan pendapatan, meningkatkan efisiensi operasional, mengoptimalkan kampanye pemasaran dan upaya layanan pelanggan, merespons lebih cepat tren pasar yang sedang berkembang dan mendapatkan keunggulan kompetitif atas pesaing - semuanya dengan tujuan akhir untuk meningkatkan kinerja bisnis. Bergantung pada aplikasi tertentu, data yang dianalisis dapat terdiri dari catatan historis atau informasi baru yang telah diproses untuk penggunaan analitik waktu-nyata. Selain itu, dapat berasal dari campuran sistem internal dan sumber data eksternal [7].

\section{Data Preprocessing}

Data preprocessing adalah langkah yang sering diabaikan tetapi merupakan langkah penting dalam proses penambangan data. Pengumpulan data biasanya merupakan proses yang dikendalikan secara longgar, sehingga berada di luar jangkauan nilai, misalnya kombinasi data yang tidak mungkin, nilai yang hilang, dan lain-lain. Menganalisis data yang belum disaring dapat membuat masalah di hasil akhir karena hasil akhir tidak sesuai dengan ekspektasi pada pengolahan data. Dengan demikian, representasi dan kualitas data adalah yang pertama dan terpenting sebelum menjalankan analisis.

Persiapan data dapat mengambil waktu yang cukup besar dalam pemrosesan. Data Preprocessing meliputi persiapan data, ditambah dengan integrasi, pembersihan, normalisasi dan transformasi data; dan tugas pengurangan data. Hasil yang diharapkan setelah rangkaian tugas pemrosesan data yang andal adalah dataset final, yang bisa dianggap benar dan bermanfaat untuk algoritma penambangan data lebih lanjut [8].

\section{Random Forest Algorithm}

Random Forest Algorithm merupakan salah satu algoritma machine learning yang digunakan sebagai klasifikasi. Klasifikasi merupakan bagian penting dari machine learning yang bertugas untuk mengelompokkan data bergantung pada kecenderungannya.

Decision Tree merupakan bagian dari Random forest, yaitu merupakan pohon keputusan untuk membedakan suatu data. Sebagai contoh, diberikan data yaitu dua angka 1 dan lima angka 0 , dan setiap angka memiliki warnanya masing masing, lalu data ingin dikelompokkan, dan fitur yang diambil dari data tersebut adalah warna dan garis bawah, maka pengerjaanya seperti gambar 1 [9].

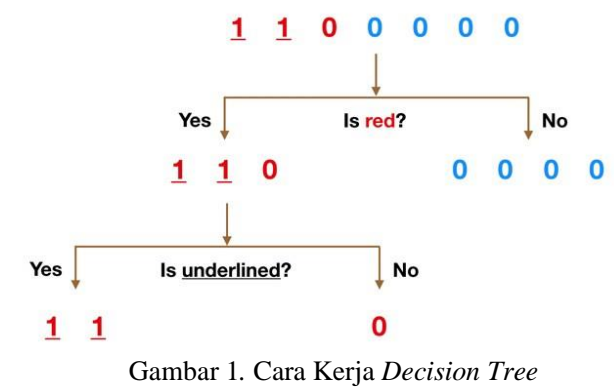

Random forest algorithm merupakan kumpulan dari decision tree yang beroperasi menjadi suatu gabungan fungsional. Setiap decision tree memiliki kesimpulan prediksi klasifikasi dan hasil prediksi akan digabungkan. Random forest algorithm memiliki hasil yang lebih baik dibandingkan dengan model individual lainnya dikarenakan Random forest algorithm menggunakan decision tree yang tidak memiliki korelasi. Kesalahan prediksi dalam satu decision tree dapat ditutupi dengan kebenaran yang 
didapatkan dari decision tree lainnya asalkan arah pembuatan decision tree benar.

Ada beberapa ketentuan agar random forest algorithm baik digunakan yaitu:

a. Decision tree harus dibuat berdasarkan sinyal kecenderungan suatu data, tidak disarankan untuk menduga kecenderungan suatu data.

b. Prediksi yang dilakukan oleh setiap decision tree harus memiliki korelasi yang rendah dengan decision tree lainnya.

Random forest algorithm dipilih untuk melakukan prediksi loan yang baik atau tidak dikarenakan beberapa hal yakni:

a. Random forest algorithm berjalan efisien pada data yang jumlahnya banyak, dan memiliki akurasi yang tinggi dibandingkan algoritma lainnya b. Dapat berjalan dengan baik dengan kelas yang populasinya tidak seimbang [4].

\section{E. Adaboost Algorithm}

Algoritma Adaboost adalah salah satu dari boosting classification algorithm yang dapat meningkatkan kelompok klasifikasi "lemah" menjadi klasifikasi "kuat". Langkah pertama pada algoritma ini biasanya menggunakan algoritma klasifikasi dasar. Kemudian menyesuaikan bobot sampel sesuai dengan hasil klasifikasi dasar, yang membuat sampel yang diklasifikasi lebih diperhatikan. Selanjutnya sampel yang disesuaikan digunakan untuk melatih base learner berikutnya. Setelah iterasi, pembobotan ditambahkan ke base learner untuk membentuk klasifikasi akhir. Cara kerja algoritma ini dapat dilihat pada gambar 2 [8].

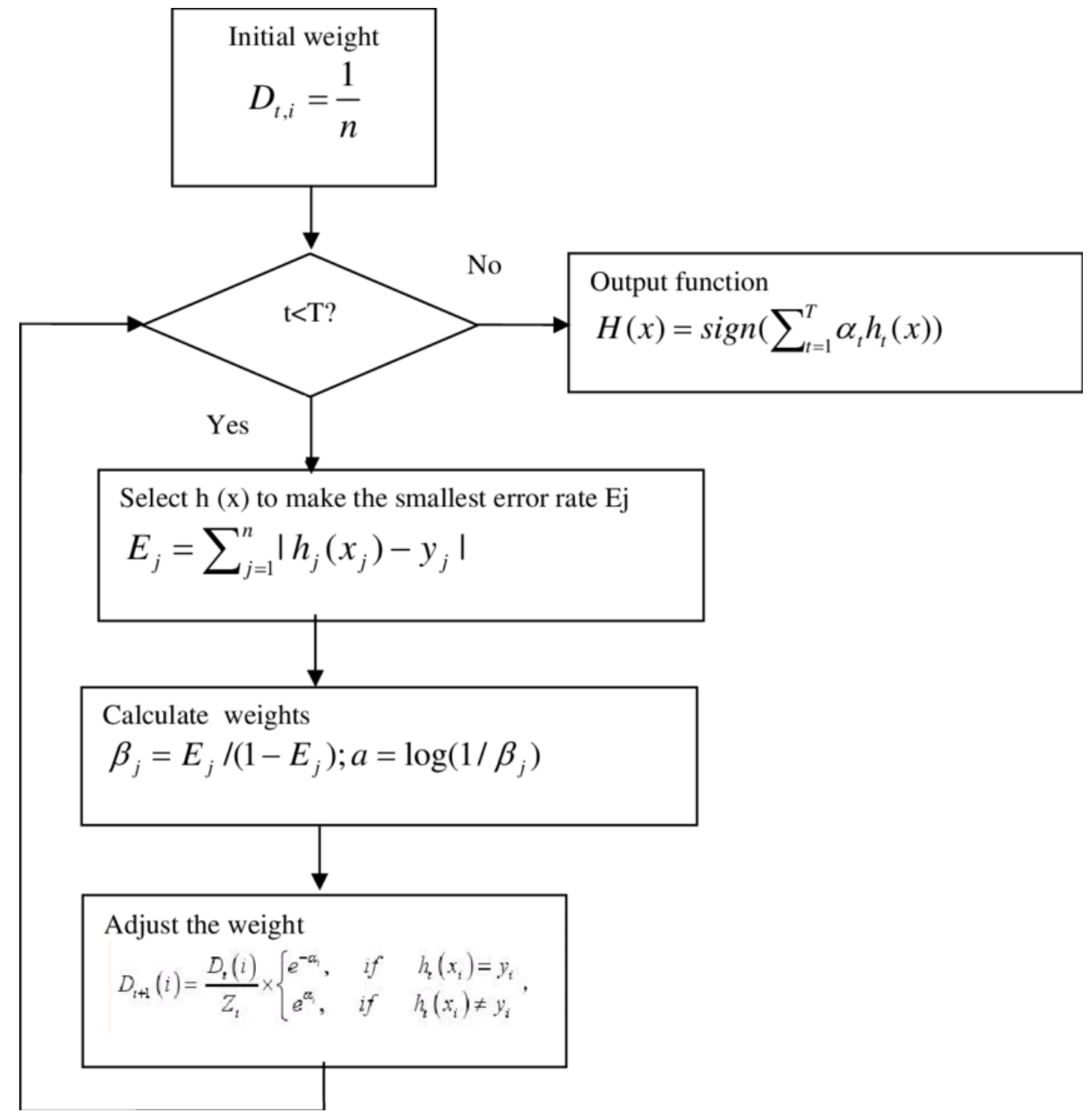

Gambar 2. Cara Kerja Adaptive Boosting

\section{F. Confusion matrix}

Confusion matrix merupakan salah satu metode yang dapat digunakan untuk mengukur kinerja suatu metode klasifikasi. Pada dasarnya confusion matrix mengandung informasi yang membandingkan hasil klasifikasi yang dilakukan oleh sistem dengan hasil klasifikasi yang seharusnya [5]. 
Berdasarkan jumlah keluaran kelasnya, sistem klasifikasi dapat dibagi menjadi 4 (empat) jenis yaitu klasifikasi binary, multi-class, multi-label dan hierarchical [12]. Pada klasifikasi binary, data masukan dikelompokkan ke dalam salah satu dari dua kelas. Jenis klasifikasi ini merupakan bentuk klasifikasi yang paling sederhana dan banyak digunakan. Contoh penggunaannya antara lain dalam sistem yang melakukan deteksi orang atau bukan, sistem deteksi kendaraan atau bukan, dan sistem deteksi pergerakan atau bukan.

\section{G. Risk assessment}

Risk assessment adalah metode yang sistematis untuk menentukan apakah suatu kegiatan/aset mempunyai risiko yang dapat diterima. Risk assessment sangat penting karena membantu menciptakan kesadaran tentang bahaya dan risiko yang didapatkan dari aset yang dimiliki. Hal ini bertujuan untuk mengurangi kemungkinan bahaya dengan menambahkan langkah-langkah pengendalian yang diperlukan dan tindakan pencegahan.

Penilaian risiko juga memprioritaskan bahaya dan membantu menentukan apakah tindakan pengendalian yang ada memadai, hal ini dilakukan untuk memeringkatkan risiko dan meyakinkan pihak manajemen bahwa terdapat risiko-risiko yang menjadi prioritas untuk dikelola secara efektif [13].

\section{H. Non-Perform Loan (NPL)}

Non-Perform Loan (NPL) adalah rasio yang menggambarkan tingkat persentase tertentu antara total kredit bermasalah dengan total kredit yang diberikan atau dengan kata lain kredit yang kolektabilitasnya masuk dalam kategori kolektabilitas tidak lancar. Dengan rumus yang diberikan sebagai berikut [13]:

$$
\text { NPL Net }=\frac{\text { Bad Loan }}{\text { Loan Amount }} \times 100 \%
$$

\section{PERANCANGAN}

\section{A. Research Design}

Perancangan penelitian ini akan menggunakan proses seperti pada gambar 3, yaitu:

a. Pengambilan data yang berhubungan dengan loan pada jangka waktu 5 tahun.

b. Menganalisis keadaan loan pada bank yang bersangkutan menggunakan risk assessment.

c. Preprocessing data atau EDA sehingga didapatkan fitur yang dapat menghasilkan model yang efektif.

d. Data processing menggunakan 3 metode yang akan dibandingkan yaitu Random forest, Random forest dan Adaptive Boosting, dan DNN.

e. Evaluasi model yang telah dibuat, lalu bandingkan performa ketiga model. 


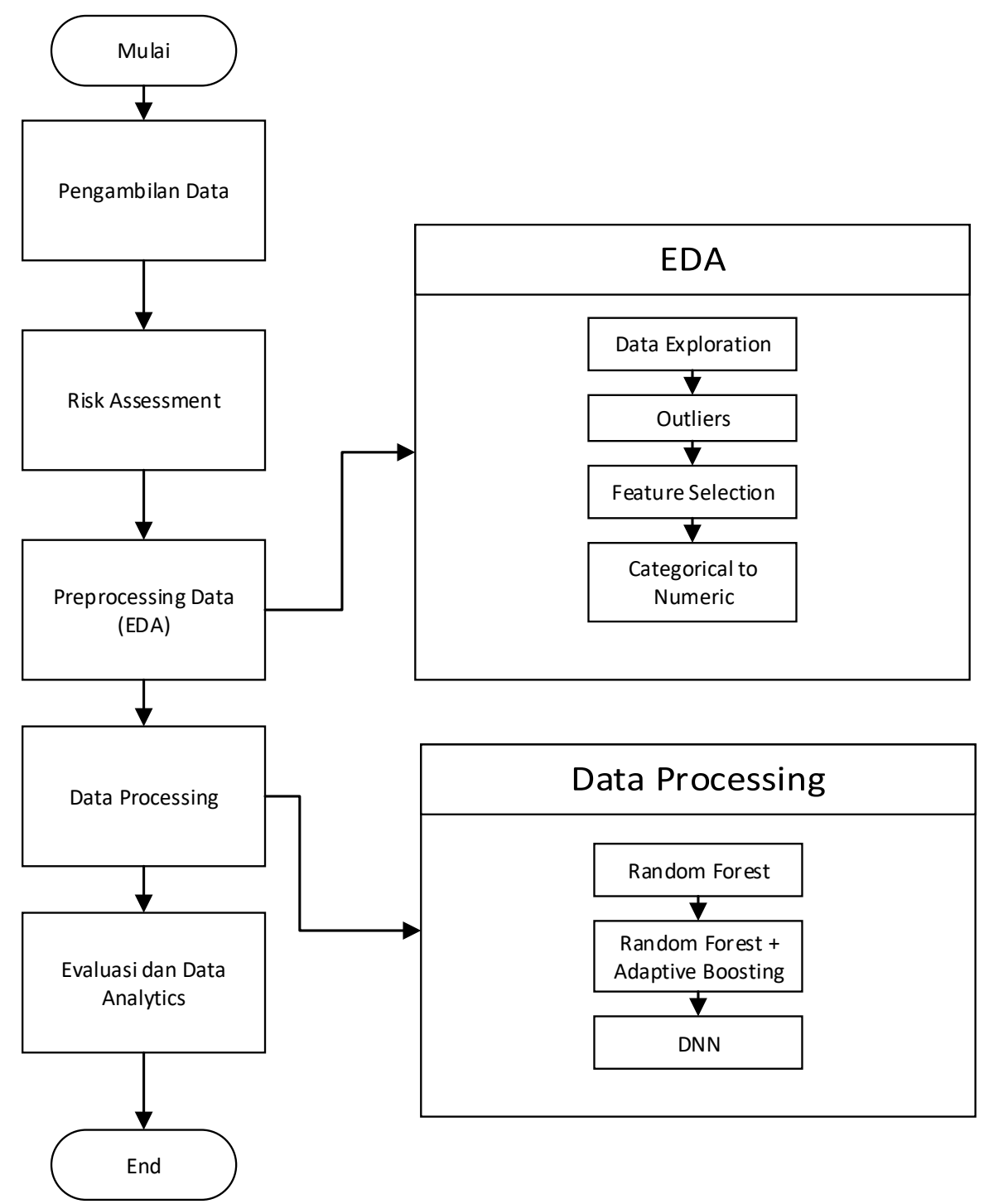

Gambar 3. Research Design

\section{B. Sumber Data}

Sumber data diperoleh dari salah satu bank di Indonesia. Data tersebut merupakan data peminjaman (loan). Data-data tersebut antara lain:

a. Data Kondisi Peminjaman

Data ini merupakan data yang akan dipakai sebagai output dari prediksi. Data terdiri dari status baik atau buruknya sebuah pinjaman.

b. Data Kepemilikan Rumah Kustomer

Data ini merupakan salah satu fitur input yang akan dipakai. Data berupa kepemilikan rumah yaitu RENT, OWN, MORTAGE, OTHER, NONE, dan ANY.

c. Data Tujuan Peminjaman

Data ini merupakan salah satu fitur input yang akan dipakai. Data berupa tujuan dilakukannya peminjaman.

d. Data Grade Peminjaman

Data ini merupakan salah satu fitur input yang akan dipakai. Data berupa klasifikasi kelas dari pinjaman.

e. Data Kategori Pendapatan

Data ini merupakan salah satu fitur input yang akan dipakai. Data berupa klasifikasi kelas dari pendapatan kustomer yang melakukan pinjaman.

f. Data lain-lain.

Data ini merupakan input fitur-fitur lain yang dapat dilihat pada gambar 4 


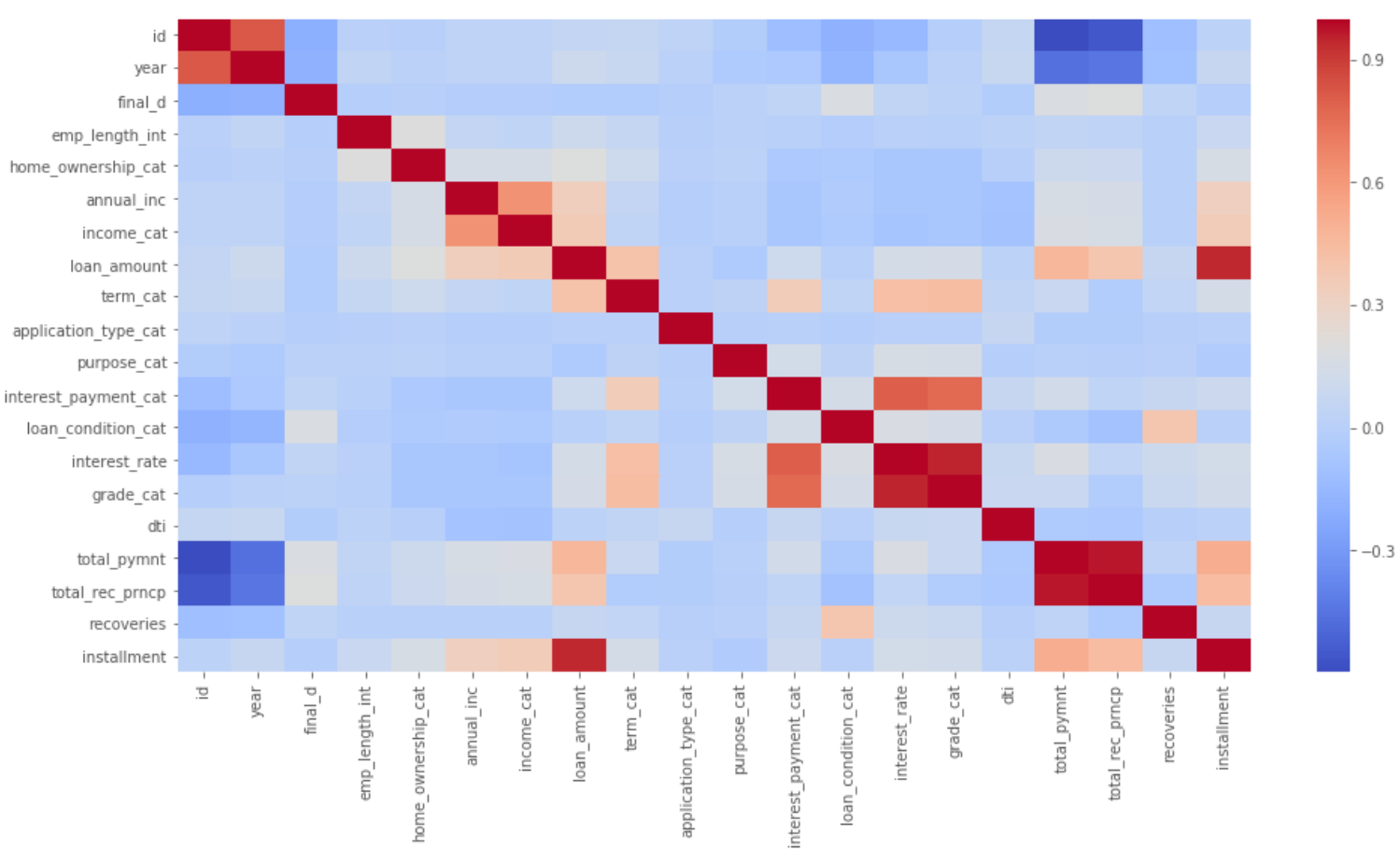

Gambar 4. Heatmap Correlation

\section{Perancangan NPL Risk assessment}

Berikut ini adalah perancangan NPL Risk assessment yang akan dipakai sebagai hasil risk assessment penelitian ini. Langkah-langkah yang digunakan:

a. Mengambil dan menghitung total pengeluaran bank terhadap loan selama 5 tahun.

b. Menghitung nilai $N P L$ setiap tahunnya.

c. Membandingkan nilai NPL, jika diatas 5\% maka bank dinyatakan tidak sehat sehingga risiko tinggi.

Risk Assessment ini dilakukan agar memastikan kualitas data bank yang dipakai merupakan data yang baik, karena data yang buruk tidak akan menghasilkan model yang baik.

\section{Pre-Processing Data}

Berikut ini adalah langkah-langkah yang dilakukan untuk tahap Preprocessing data :

a. Melihat korelasi data menggunakan pearson dan heatmap, dapat dilihat pada gambar 4. Korelasi berkisar dari 0 hingga 1 .

Nilai yang mendekati nol (warna biru) berarti tidak ada tren linier antara kedua variabel. Semakin dekat ke nilai 1 (warna merah), semakin berkorelasi positif.

b. Membuat fitur kondisi pinjaman menjadi nilai 1 dan 0 , Jika kondisi pinjaman baik maka nilai 0 dan sebaliknya.

c. Membuang fitur yang dianggap tidak penting untuk pemrosesan data.

d. Mengubah fitur lamanya bekerja, menggunakan Min max scaler.

e. Melihat hubungan fitur kepemilikan rumah dengan kondisi pinjaman menggunakan countplot, hasil dapat dilihat pada gambar 5.

Jika dilihat untuk kepemilikan "OTHER, NONE, dan $A N Y$ " tidak berdampak pada data kondisi pinjaman yang ditandakan oleh nilai 0 dan 1 karena jumlahnya sangat sedikit atau bahkan tidak ada, sehingga fitur ini dapat dibuang.

f. Melihat hubungan antara fitur lain dengan kondisi pinjaman.

g. Menggunakan boxplot untuk mendeteksi adanya Outlier, boxplot ini ditampilkan pada gambar 6. Jika dilihat terdapat cukup banyak data outlier sehingga data harus dipangkas agar tidak berdampak pada akurasi model.

h. Membandingkan besaran installment dengan keadaan pinjaman dengan menggunakan histogram plot, hasilnya dapat dilihat pada gambar 7 .

i. Setelah diketahui properties dari setiap data, maka dilakukan pemangkasan data yang dianggap outlier, perubahan jenis data agar menghemat memory, dan perubahan data klasifikasi menggunakan metode onehot encode.

j. Pembagian data test dan data train, pada penelitian ini adalah $70 \%: 30 \%$. 


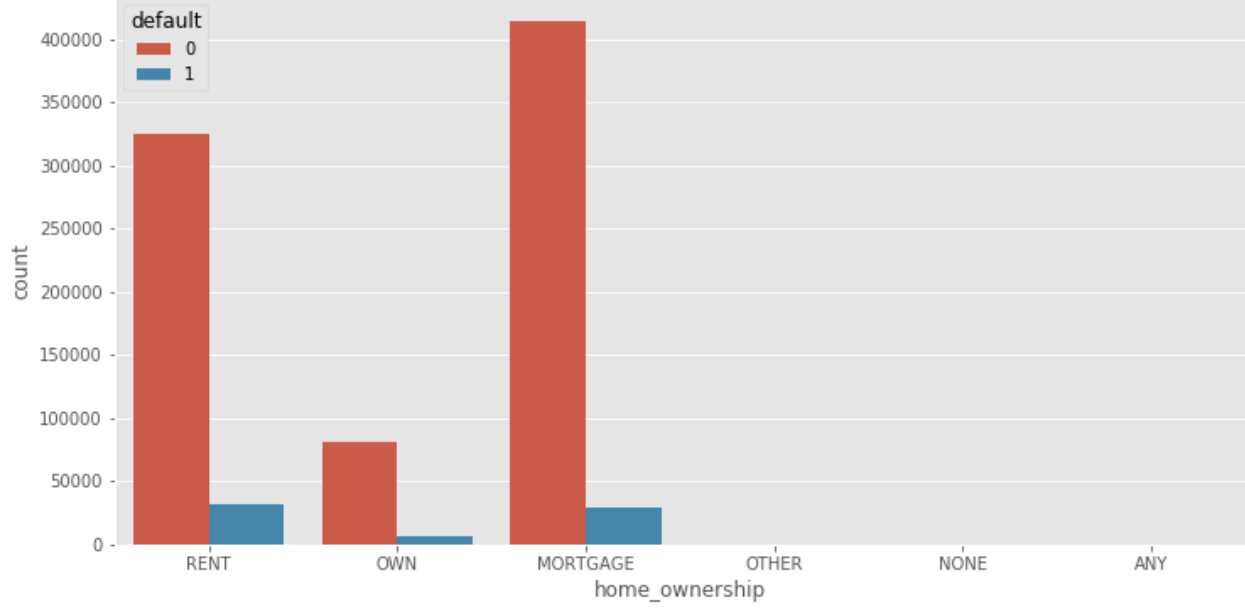

Gambar 5. Hubungan Kepemilikan Rumah dengan Kondisi Pinjaman

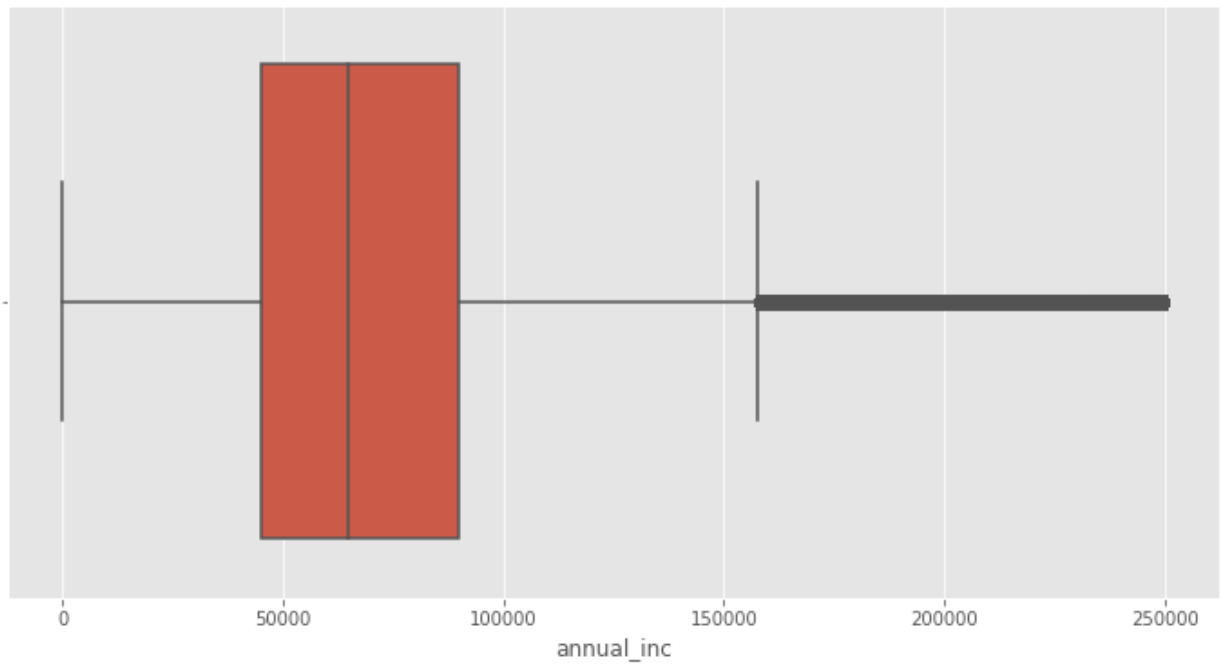

Gambar 6. Penggunaan Boxplot untuk Mencari Outlier

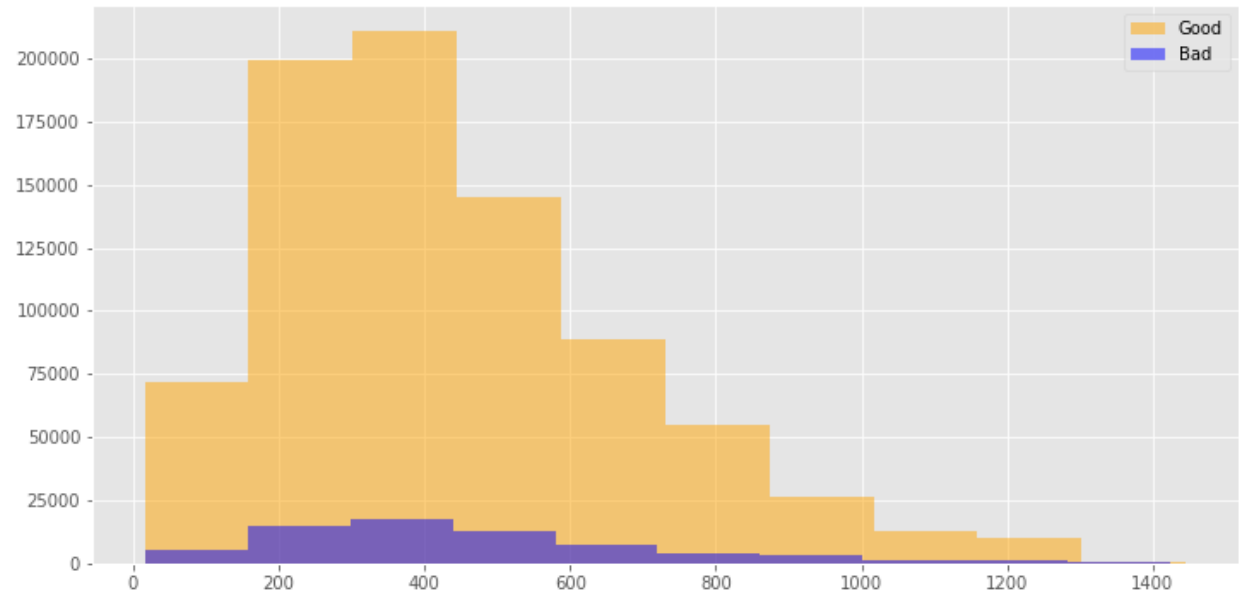

Gambar 7. Hubungan Installment Rumah dengan Kondisi Pinjaman 


\section{E. Perancangan Model Random Forest (Baseline)}

Berikut ini adalah perancangan model Random forest yang akan dipakai sebagai base learner untuk Adaboost algorithm. Model dapat dilihat pada flowchart gambar 8 .
Pada model yang dirancang Random forest ditetapkan untuk memiliki 100 cabang Decision Tree, gini criterion, dan "best" splitter.

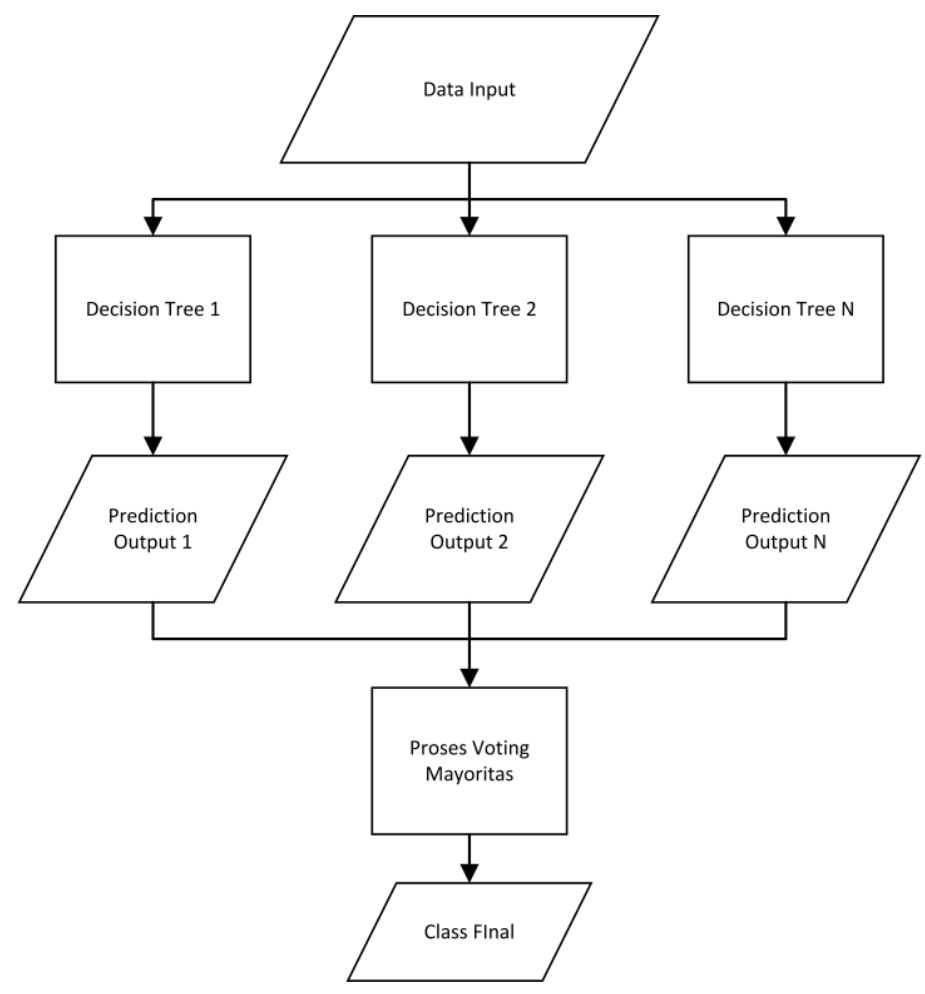

Gambar 8. Flowchart Model Random Forest

\section{F. Perancangan Model Adaboost Algorithm}

Berikut ini adalah perancangan model Adaboost menggunakan random forest algorithm yang sebelumnya dibuat sebagai base learnernya.

TABEL I

TREND NON-PERFORM LOAN (NPL) BANK DALAM 5 TAHUN TERAKHIR

\begin{tabular}{|c|c|c|c|c|c|}
\hline Tahun & Total (Rp) & $\begin{array}{l}\text { Uang Masuk (Bad } \\
\text { Loan) }(\mathrm{Rp})\end{array}$ & $\begin{array}{c}\text { Uang Masuk (Good } \\
\text { Loan) }(\mathrm{Rp})\end{array}$ & $N P L$ & Kenaikan \\
\hline 2011 & 261.683 .825 & 25.209 .111 & 258.419 .151 & 0.10 & 0.01 \\
\hline 2012 & 718.411 .025 & 74.555 .875 & 698.316 .879 & 0.10 & -0.03 \\
\hline 2013 & 1.981 .989 .025 & 154.381 .839 & 1.720 .877 .961 & 0.08 & -0.04 \\
\hline 2014 & 3.503 .830 .175 & 127.871 .407 & 2.099 .869 .695 & 0.04 & -0.03 \\
\hline 2015 & 6.417 .580 .175 & 31.130 .055 & 1.295 .165 .135 & 0.00 & 0.00 \\
\hline
\end{tabular}


Flowchart untuk model Adaboost dapat dilihat pada gambar 9. Pada model ini ditetapkan untuk melakukan 100 kali iterasi

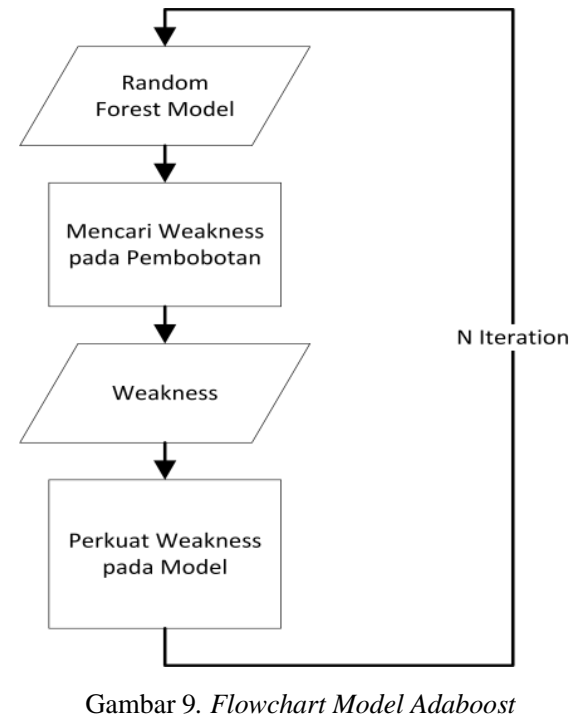

\section{G. Perancangan Model DNN}

Berikut ini adalah perancangan model DNN yang akan dipakai sebagai pembanding pada saat benchmarking model yang ada pada penelitian ini. Hal ini dilakukan untuk membandingkan performa metode machine learning yang digunakan dengan metode deep learning. Model DNN digunakan sebagai pembanding karena model DNN merupakan metode klasifikasi deep learning yang cukup baik dan mudah digunakan. Berikut parameter-parameter yang digunakan:
a. Batch Size: 10000
b. Epoch: 1000
c. Shuffle: True
d. Features: [emp_length, ann_inc, loan_amt, int_rate, dti, mortgage, own, rent, high, low, medium, short, long, credit, debt, low_int]
e. Classes: 2

\section{HASIL EKSPERIMEN DAN EVALUASI}

\section{A. Hasil Analisis Risk Assessment NPL}

TABEL II

TOTAL DANA YANG SUDAH DIKELUARKAN SELAMA 5 TAHUN

\begin{tabular}{|l|l|l|l|l|}
\hline 2011 & 2012 & 2013 & 2014 & 2015 \\
\hline Rp. & Rp. & Rp. & Rp. & Rp. \\
261.683. & 718.411. & 1.981 .989 & 3.503 .830 & 6.417 .580 \\
825 & 025 & .225 & .175 & .175 \\
\hline
\end{tabular}

Pada tabel I ditampilkan data tren Non-Perform Loan (NPL) bank dalam 5 tahun terakhir. Berdasarkan tabel II, dari tahun 2011 hingga 2015 total peminjaman bank yang bersangkutan selalu mengalami kenaikan. Jika dilihat dari tabel I, maka perhitungan $N P L$ nilainya $<5 \%$.

Menurut Peraturan Bank Indonesia Nomor 6/10/PBI/2004 tanggal 12 April 2004 tentang Sistem Penilaian Tingkat Kesehatan Bank Umum, semakin tinggi nilai NPL (diatas $5 \%$ ) maka bank tersebut tidak sehat. Semakin tinggi nilai NPL maka semakin tinggi risiko kredit yang akan ditanggung pihak bank, sesuai dengan Peraturan Bank Indonesia [10].

$N P L$ yang tinggi menyebabkan menurunnya laba yang akan diterima oleh bank. Penurunan laba mengakibatkan dividen yang dibagikan juga semakin berkurang sehingga pertumbuhan tingkat return saham bank akan mengalami penurunan.

Sesuai dengan data pada tabel I, nilai $N P L$ bank masih dalam batas toleransi yang diatur dalam undang-undang. Dengan ini, kita dapat menyimpulkan bahwa data ini cukup baik untuk digunakan. Tetapi data yang dipakai mempunyai masalah yaitu penyebaran data yang tidak merata.

\section{B. Hasil Percobaan pada Model Random Forest}

TABEL III

HASIL MODEL RANDOM FOREST

\begin{tabular}{|l|l|l|}
\hline N-Tree & Accuracy & Recall Rate \\
\hline 10 & $42.3432 \%$ & $0.1612 \%$ \\
\hline 30 & $63.13421 \%$ & $0.2754 \%$ \\
\hline 50 & $84.6431 \%$ & $0.2912 \%$ \\
\hline 70 & $90.0213 \%$ & $0.3123 \%$ \\
\hline 100 & $92.2998 \%$ & $0.3545 \%$ \\
\hline
\end{tabular}

Pada tabel III, ditampilan accuracy maksimal pada jumlah Decision Tree dari 10 sampai dengan 100. Jika diperhatikan akurasi dari model sangat tinggi tetapi recall rate sangat rendah. Hal ini mungkin dikarenakan distribusi data yang tidak seimbang. Dari model ini juga didapatkan Confusion matrix seperti pada gambar 10.

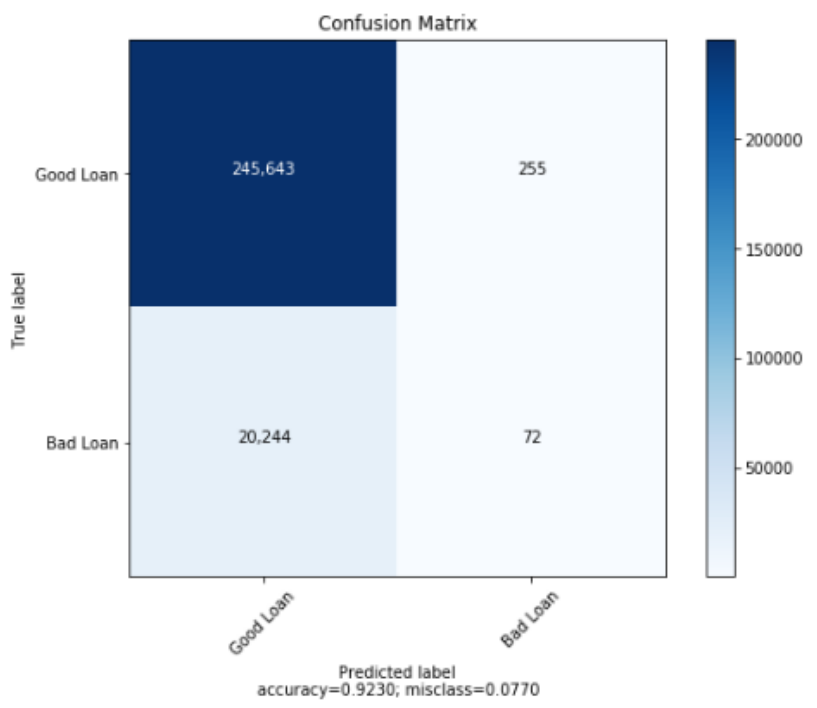

Gambar 10. Confusion matrix Model Random Forest 


\section{Hasil Percobaan pada Model Adaboost}

TABEL IV

HASIL MODEL ADABOOST

\begin{tabular}{|l|l|l|l|}
\hline N-Tree & N-Iteration & Accuracy & Recall Rate \\
\hline 100 & 10 & $39.5543 \%$ & $0.0413 \%$ \\
\hline 100 & 30 & $43.54213 \%$ & $2.1237 \%$ \\
\hline 100 & 50 & $62.431 \%$ & $3.3522 \%$ \\
\hline 100 & 70 & $82.1103 \%$ & $5.2331 \%$ \\
\hline 100 & 100 & $89.7105 \%$ & $7.4522 \%$ \\
\hline
\end{tabular}

Pada tabel IV, terlihat bahwa dengan menggunakan model ini recall rate dapat ditingkatkan dengan tradeoff accuracy yang tidak terlalu besar. Dengan model ini didapatkan juga confusion matrix yang dapat dilihat pada gambar 11.

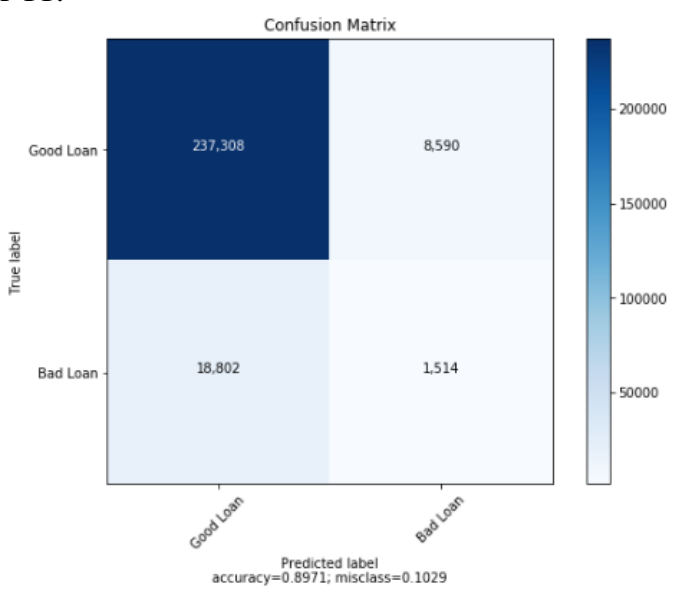

Gambar 11. Confusion matrix Model Adaboost

Jika diperhatikan pada gambar 10 dan gambar 11, terdapat error type I (false positive) dan error type II (false negative) yang jumlahnya cukup banyak. Hal ini terjadi dikarenakan sebaran data yang tidak seimbang antara good dan bad loan.

\section{Hasil Percobaan pada Model DNN}

TABEL V HASIL MODEL DNN

\begin{tabular}{|l|l|l|}
\hline Global Step & Loss & Exec. Time (sec) \\
\hline 100 & 0.6911358 & 12.449 \\
\hline 2800 & 0.58773583 & 12.833 \\
\hline 4100 & 0.5654046 & 12.681 \\
\hline 4900 & 0.86097443 & 14.436 \\
\hline
\end{tabular}

Pada tabel $\mathrm{V}$, terlihat bahwa dengan menggunakan model DNN ini didapatkan loss terkecil dengan execution time yang cukup baik pada global step 4100. Selanjutnya akan digunakan parameter global step 4100 untuk pengukuran accuracy dan recall rate-nya. Dengan cara ini didapatkan:

a. Accuracy: $92.368543 \%$

b. Recall rate: $0.0000213 \%$

Tanpa ada perubahan data sampel dapat disimpulkan bahwa model DNN memiliki akurasi tertinggi. Model Random forest dengan Adaboost memiliki recall rate tertinggi. Tetapi nilai recall rate pada DNN masih sangat rendah, hal ini mungkin dikarenakan distribusi data yang tidak seimbang pada fitur kondisi peminjaman yaitu "Good Loan" dan "Bad Loan". Oleh karena itu, selanjutnya akan dilakukan analisis jika dilakukan undersampling pada jumlah data mayoritas.

\section{E. Hasil Percobaan pada Model setelah dilakukan Undersampling}

TABEL VI

HASIL MODEL SETELAH DILAKUKAN UNDERSAMPLING

\begin{tabular}{|c|c|c|c|}
\hline Ratio & Model & Accuracy & Recall Rate \\
\hline \multirow[t]{3}{*}{0.2} & $\mathrm{RF}$ & $90.628 \%$ & $7.70312 \%$ \\
\hline & $\begin{array}{l}\mathrm{RF}+ \\
\text { Adaboost }\end{array}$ & $77.195 \%$ & $30.725 \%$ \\
\hline & $D N N$ & $82.431 \%$ & $0.0352 \%$ \\
\hline \multirow[t]{3}{*}{0.4} & $\mathrm{RF}$ & $84.5241 \%$ & $26.9836 \%$ \\
\hline & $\begin{array}{l}\mathrm{RF}+ \\
\text { Adaboost }\end{array}$ & $70.50681 \%$ & $41.6667 \%$ \\
\hline & $D N N$ & $65.3541 \%$ & $2.8414 \%$ \\
\hline \multirow[t]{3}{*}{0.6} & $\mathrm{RF}$ & $76.3772 \%$ & $43.96535 \%$ \\
\hline & $\begin{array}{l}\mathrm{RF}+ \\
\text { Adaboost }\end{array}$ & $65.4514 \%$ & $49.03032 \%$ \\
\hline & $D N N$ & $64.4312 \%$ & $4.71872 \%$ \\
\hline \multirow[t]{3}{*}{0.8} & $\mathrm{RF}$ & $68.9265 \%$ & $57.08309 \%$ \\
\hline & $\begin{array}{l}\mathrm{RF}+ \\
\text { Adaboost }\end{array}$ & $63.1454 \%$ & $56.86158 \%$ \\
\hline & $D N N$ & $46.2341 \%$ & $12.54814 \%$ \\
\hline \multirow[t]{3}{*}{1.0} & $\mathrm{RF}$ & $62.1552 \%$ & $66.02678 \%$ \\
\hline & $\begin{array}{l}\mathrm{RF}+ \\
\text { Adaboost }\end{array}$ & $57.9481 \%$ & $59.0126 \%$ \\
\hline & $D N N$ & $45.6324 \%$ & $21.5657 \%$ \\
\hline
\end{tabular}

Pada tabel VI, terlihat mulai muncul model yang cukup baik. Model yang baik memiliki accuracy dan recall rate yang tinggi. Jika dilihat model DNN tidak beroperasi cukup bagus ketika dilakukan undersampling terhadap data. Model Random Forest muncul sebagai model yang paling bagus ketika dilakukan undersampling. Grafik perbandingan performa antara Random Forest dan Random Forest dan Adaboost dapat dilihat pada gambar 12 . 


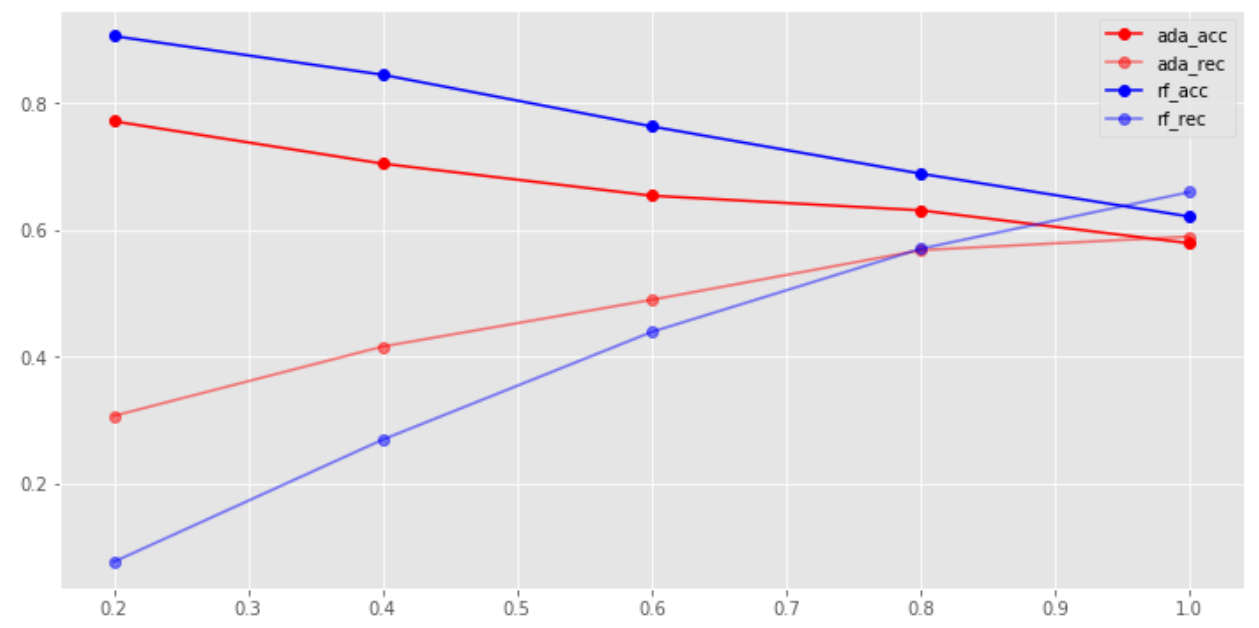

Gambar 12. Perbandingan antara Model RF dan RF + Adaboost

\section{KESIMPULAN DAN SARAN}

\section{A. Kesimpulan}

Pada perbandingan ketiga metode, DNN unggul pada akurasi dari prediksi modelnya. Adaptive Boosted Random forest menunjukkan akurasi terendah dari ketiga metode yang diuji tetapi menunjukkan recall rate yang tertinggi dibandingkan yang lain. Undersampling data dapat meningkatkan akurasi dan recall rate dari random forest pada kasus data ini.

Sesuai dengan tren data dalam 5 tahun terakhir, bank yang diteliti tidak terindikasi melanggar peraturan PBI Nomor 6/10/PBI/2004 tanggal 12 April 2004 mengenai NPL diatas 5\%. NPL Bank masih dalam batas toleransi yang diatur undang-undang.

\section{B. Saran}

Sebaiknya model digunakan dalam proses indikasi risk loan default secara real dilapangan sehingga dapat dibandingkan hasil yang didapat dibandingkan cara konvensional.

\section{UCAPAN TERIMA KASIH}

Terima kasih diucapkan sebesar - besarnya kepada para pengajar dan staf Fakultas Teknologi Informasi, Program Studi Magister Ilmu Komputer Universitas Kristen Maranatha Bandung atas dukungan dan bantuannya dalam pelaksanaan penelitian ini.

\section{DAFTAR PUSTAKA}

[1] B. Chang, R. Yang, C. Guo, S. Ge, and L. Li, "A new application of optimized random forest algorithms in intelligent fault location of rudders," IEEE Access, vol. 7, pp. 94276-94283, 2019, doi 10.1109/ACCESS.2019.2926109.

[2] L. Zhu, D. Qiu, D. Ergu, C. Ying, and K. Liu, "A study on predicting loan default based on the random forest algorithm," Procedia Computer Science, vol. 162, pp. 503-513, 2019, doi: 10.1016/j.procs.2019.12.017.

[3] M. Sokolova and G. Lapalme, "A systematic analysis of performance measures for classification tasks," Information processing \& management, vol. 45, no. 4, pp. 427-437, 2009.

[4] J. R. Koza, F. H. Bennett, D. Andre, and M. A. Keane, Automated Design of Both the Topology and Sizing of Analog Electrical Circuits Using Genetic Programming, Artificial Intelligence in Design '96, Dordrecht: Nederland, Springer, 1996, pp. 151-170.

[5] E. Prasetyo, Data Mining Konsep dan Aplikasi Menggunakan Matlab, Yogyakarta, Andi, 2012.

[6] S. Garcia, J. Luengo, F. Herrera, Data Preprocessing in Data Mining, seri Intelligent Systems Reference Library, Switzerland, Springer, 2014.

[7] F. Provost and T. Fawcett, Data Science for Business: What You Need to Know about Data Mining and Data-Analytic Thinking, 1. ed., 2. release. Beijing: O’Reilly, 2013.

[8] F. Wang, Z. Li, F. He, R. Wang, W. Yu, and F. Nie, "feature learning viewpoint of adaboost and a new algorithm," IEEE Access, vol. 7, pp. 149890-149899, 2019, doi: 10.1109/ACCESS.2019.2947359.

[9] C. Jiang, Z. Wang, R. Wang, and Y. Ding, "Loan default prediction by combining soft information extracted from descriptive text in online peer-to-peer lending," Ann Oper Res, vol. 266, no. 1-2, pp. 511-529, Jul. 2018, doi: 10.1007/s10479-017-2668-z.

[10] H. Darmawi, Manajemen Risiko, Jakarta : Bumi Aksara, 2010.

[11] P. K. Ozili, "Non-performing loans and financial development: new evidence," The Journal of Risk Finance, vol. 20, no. 1, pp. 5981, Jan. 2019, doi: 10.1108/JRF-07-2017-0112.

[12] C. M. Bishop, Pattern Recognition and Machine Learning. New York: Springer, 2006.

[13] T. Aven, "Risk assessment and risk management: review of recent advances on their foundation," European Journal of Operational Research, vol. 253, no. 1, pp. 1-13, Aug. 2016, doi: 10.1016/j.ejor.2015.12.023. 